\title{
The natural course of hepatitis $C$ virus infection 18 years after an epidemic outbreak of non-A, non-B hepatitis in a plasmapheresis centre
}

\author{
C Datz, M Cramp, T Haas, O Dietze, H Nitschko, G Froesner, N Muss, F Sandhofer, \\ W Vogel
}

\begin{abstract}
Background-The natural history of hepatitis $C$ virus (HCV) infection is variable and factors determining the course of the illness are unclear.

Aims-To determine the natural course of HCV infection in a well characterised group of patients 18 years after an epidemic outbreak of non-A, non-B hepatitis at a plasmapheresis centre.

Methods-Between 1994 and 1996, 20 of 30 affected individuals were studied. HCV infection was confirmed using second and third generation ELISA test kits. HCV RNA was detected by a polymerase chain reaction (PCR) method and HCV genotyping was performed by analysing amplicons from the conserved 5'-nontranslated region generated by nested PCR. Thirty two liver biopsies were carried out in 14 patients.

Results-HCV antibodies were detected in all subjects. Eighteen patients had abnormal liver enzymes and 17 were HCV RNA positive, all of whom were infected with genotype 1a. Ninety per cent of this cohort showed evidence of chronic HCV infection with $50 \%$ having progressive liver disease and $20 \%$ cirrhosis 18 years after acute onset of non-A, non-B hepatitis. Considerable variation in disease outcome occurred between individuals and no correlation with clinical features of the acute illness was found.

Conclusions-Variability in the consequences of $\mathrm{HCV}$ infection in cases infected with the same virus suggests that host factors are important in determining disease outcome. The factors which determine differences in the natural history of the disease still remain to be elucidated. (Gut 1999;44:563-567)
\end{abstract}

Keywords: non-A, non-B hepatitis; plasmapheresis; hepatitis C; natural course; disease progression

Studies, King's College Hospital, London, UK M Cramp

Max von

Pettenkofer-Institut, University of Munich, Munich, Germany

H Nitschko

G Froesner

Correspondence to: Dr Datz.

Accepted for publication 23 September 1998
RNA remaining detectable over many years. ${ }^{34}$ Chronic HCV infection can run a mild course with little or no morbidity but the long term sequelae have been found to differ widely in different studies. ${ }^{5-11}$ Progression to cirrhosis will occur in up to $30 \%$ of all cases ${ }^{5-8}$ and the risk of developing hepatocellular carcinoma (HCC) after longstanding infection is clearly increased. ${ }^{812} 13$ The reason why some people and not others develop severe disease may be determined by the effect of a large number of both host and viral variables that can influence disease progression. Host factors that may play a role include route of infection, ${ }^{914}$ the size of the infecting innoculum, patient sex, age at time of infection, and alcohol consumption. ${ }^{6}$ Viral factors of relevence include the viral genotype, ${ }^{15}$ viral load, ${ }^{16}$ and genetic heterogeneity, ${ }^{18-20}$ together with coinfection with hepatitis B virus (HBV) ${ }^{21}$ or HIV. ${ }^{22}$

Many of the factors that influence disease progression remain poorly understood and the relative importance of host and viral factors in determining outcome is not known. In an attempt to clarify the factors that predict the pattern of HCV disease progression in an individual we have looked in detail at a well defined cohort of patients, all of whom became infected with HCV while donating plasma over a period of three months in 1977 and 1978.

\section{Patients and methods}

In $1977 / 78$ an epidemic outbreak of non-A, non-B hepatitis occurred in a plasmapheresis centre in Salzburg, Austria, involving 30 donors. Epidemiological data ${ }^{23}$ suggested spread within the centre. The mode of transmission remained speculative but was believed to be due to contaminated plastic bags used for reinfusing erythrocytes. Hepatitis A (HAV) and B (HBV) virus infection, cytomegalovirus, and Epstein Barr virus infection were excluded serologically. Neither parenteral or oral drug abuse, nor chronic alcoholism could be found within the diseased population. A chimpanzee previously exposed to both HAV and HBV was inoculated parenterally with blood of one donor; the animal subsequently developed abnormal aminotransferases, histologically proved hepatitis, and characteristic tubular alterations in the endoplasmatic reticulum confirming the diagnosis of non-A, non-B hepatitis. Infections were detected over a

Abbreviations used in this paper: HBV, hepatitis B virus; $\mathrm{HCC}$, hepatocellular carcinoma; $\mathrm{HCV}$, hepatitis C virus; NTR, non-translated region. 
period of several months with two well defined peaks in December 1977 and end of January and beginning of February 1978, when the plasmapheresis centre was closed down.

Abnormal liver enzymes were found in all 30 donors between 27 and 59 days (mean 41 days) after plasma donation and 27 of them were hospitalised. Sixteen patients (59\%) had uncharacteristic subjective symptoms such as nausea, loss of appetite, or fatigue, six (22\%) exhibited elevated body temperatures between 37.5 and $38^{\circ} \mathrm{C}$, nine $(33 \%)$ had jaundice with bilirubin concentrations above $3 \mathrm{mg} \%$, one (3.6\%) developed arthritis of the big joints, and $11(41 \%)$ were asymptomatic. The mean age at time of infection was 24.4 years (range 19-35).

These patients have been studied prospectively since the outbreak although nine of the original cohort of 30 patients have been lost to follow up and one died in 1991 at the age of 53 years due to a non-liver related cause but showed clinical evidence of chronic hepatitis. In the present study we report on the findings from the remaining 20 plasma donors 18 years after the outbreak of non-A, non-B hepatitis. We have looked at viral markers, host variables, and features of the acute hepatitis in this cohort in an attempt to clarify factors that are associated with different patterns of disease progression.

\section{LABORATORY TESTS}

The presence of hepatitis $\mathrm{C}$ virus antibodies was established by second and third generation ELISA kits (Abbott Labs, North Chicago, Illinois, USA). The presence or absence of HCV RNA was determined by a polymerase chain reaction (PCR) method (Amplicor, Hoffmann-La Roche). HCV genotyping was performed by analysing amplicons from the conserved 5'-non-translated region (NTR) generated by nested reverse transcription (RT) PCR.

\section{HCV RT-PCR AND GENOTYPING}

Primers

The following primers were used for RT and PCR: RT, primer 11 (antisense) 5'-GTG CAC GGT CTA CGA GAC C. PCR (first round): primer 10 (sense) 5'-GGC GAC ACT CCA CCA TRR A and primer 11 (323 nt amplicon). PCR (nested) primer 15 (sense) 5'-CAC TCC CCT GTG AGG AAC T and primer 16 (antisense) 5'-CCC GGG GCA CTC GCA AGC A (283 nt amplicon). All primers are located in the higly conserved 5'-NTR of HCV.

\section{Isolation of HCV RNA, RT, and PCR}

Isolation of HCV RNA was performed from serum or plasma using the QiAamp Viral isolation kit (Qiagen, Hilden) according to the instructions of the manufacturer. Briefly, 140 $\mu \mathrm{l}$ of the sample was lysed for 10 minutes at room temperature, mixed with ethanol, and centrifuged in a spin column. The bound RNA was washed and then eluted in a final volume of $50 \mu \mathrm{l}$.

Reverse transcription was done in a volume of $20 \mu \mathrm{l}$ at $42^{\circ} \mathrm{C}$ for one hour using the Super- script RT-Kit (Gibco; $0.2 \mu$ l enzyme/reaction), $10 \mu \mathrm{l}$ of the isolated RNA, and $20 \mathrm{pmol}$ of primer 11. PCR was performed in two rounds of amplification, using primers 10 and 11 for the first and primers 15 and 16 for the nested PCR and 1.5 U Taq-Polymerase (Perkin Elmer) in a final volume of $50 \mu \mathrm{l}$. Cycling conditions were: $94^{\circ} \mathrm{C}$ for four minutes, 35 cycles of $94^{\circ} \mathrm{C}$ for 30 seconds, $50^{\circ} \mathrm{C}$ for one minute, $72^{\circ} \mathrm{C}$ for two minutes, and a final step of $72^{\circ} \mathrm{C}$ for eight minutes for the first PCR: $3 \mu \mathrm{l}$ of first round product was used as template for the second round of amplification under identical cycling conditions. PCR amplicons were analysed by electrophoresis on $2 \%$ TBE-agarose gels and visualised by ethidium bromide staining. Nucleic acid extraction, amplification, and detection were performed in separate rooms.

$H C V$ genotyping by restriction fragment length polymorphism

The amplified PCR product generated by nested PCR was cleaved with different restriction enzymes according to the protocol of the manufacturers. The restriction enzymes BsmAI, BsrI, DrdI, FokI, and NciI were from New England Biolabs (Schwalbach-Taunus, Germany); HinfI, Sau3AI, and SmaI were from Boehringer Mannheim (Mannheim, Germany). The amount of DNA to be cut (50-100 ng/reaction) was adjusted by estimating the quantity of amplified product by agarose gel electrophoresis. The DNA restriction fragments were analysed on 2\% TBE-agarose gels using Boehringer Marker $\mathrm{V}$ as standard (Boehringer Mannheim).

A conserved Smal restriction site at position $-211^{24}$ is found in all common HCV genotypes and can be used to verify the authenticity of the PCR fragments. Genotype 1 can be discriminated by fragmentation with DrdI and further subdivided into type $1 \mathrm{a}$ or $1 \mathrm{~b}$ by BsmAI. A BsrI site is found in genotype 2 amplicons, which can be further differentiated into type $2 \mathrm{a}$ or $2 \mathrm{~b}$ using NciI. Type 3a is identified by a unique Sau3AI site, whereas type 4 is characterised by cutting with HinfI and FokI. ${ }^{24}$

Histological DiagNosis

Since 1978, 33 transcutaneous liver biopsies were performed in 14 patients. Of the six patients not biopsied, two had signs of cirrhosis and biopsy was not performed because of abnormal coagulation tests, two had serological evidence of chronic $\mathrm{HCV}$ infection but refused liver biopsy, and the remaining two were asymptomatic with normal aminotransferases and undetectable HCV RNA so that liver biopsy was not felt to be clinically indicated. All samples were fixed in formalin, embedded in paraffin wax and stained with haematoxylin and eosin, chromotrope anilin blue, Perl's iron stain, PAS after diastase digestion, and Shikata's orcein. Grading for activity and staging of fibrosis was performed by the same pathologist who was blinded in terms of date of biopsy and patient. Histological diagnosis was based on the classification of chronic hepatitis proposed by Desmet et al. ${ }^{25}$ Grading of chronic hepatitis activity included three cat- 
Table 1 Biochemical and histopathological findings in 20 patients during acute illness and data from follow up investigations

\begin{tabular}{|c|c|c|c|c|c|c|c|c|c|c|c|}
\hline Patient & $A L T^{\star}$ & Bilirubint & 1978 & 1979 & 1981 & 1982 & 1984 & 1989 & 1994 & 1995 & 1996 \\
\hline BA & 475 & NA & $\mathrm{a}-\mathrm{b} / 0-1$ & $\mathrm{a}-\mathrm{b} / 0$ & & & & & & & LTX 97 \\
\hline $\mathrm{BP}$ & 340 & 1.1 & $a-b / 0$ & & & & & & & $b / 1$ & \\
\hline DF & 374 & 1.5 & $\mathrm{~b} / 2$ & & & & & & & & $\mathrm{a} / 0$ \\
\hline $\mathrm{HM}$ & 768 & 1.8 & $\mathrm{c} / 0$ & & & & & & & $\mathrm{a} / 0$ & \\
\hline HEJ & 894 & 3.8 & & $a-b / 0$ & & $\mathrm{~b} / 0-1$ & $\mathrm{~b} / 1$ & & & & $\mathrm{a} / 0$ \\
\hline $\mathrm{HH}$ & 632 & NA & & $\mathrm{b} / 0$ & $\mathrm{~b} / 0$ & & & & & $\mathrm{c} / 2$ & \\
\hline $\mathrm{KH}$ & 575 & 2.8 & $\mathrm{~b} / 1$ & & $\mathrm{a}-\mathrm{b} / 0-1$ & & & & & & $a-b / 0$ \\
\hline PP & 990 & 1.9 & $a-b / 0$ & & & & & $\mathrm{a}-\mathrm{b} / 0-1$ & & $\mathrm{~b} / 1$ & \\
\hline RI & 588 & 1.0 & $\mathrm{~b} / 1$ & & & & & $\mathrm{~b} / 0-1$ & LTX & & \\
\hline SC & 350 & 1.7 & $\mathrm{c} / 0$ & & & & & & & $a-b / 0$ & \\
\hline SR & 259 & 1.1 & $a-b / 0$ & $\mathrm{c} / 0$ & & $\mathrm{~b} / 0$ & & & & $a-b / 0$ & \\
\hline HAJ & 1027 & 4.9 & & & & & & & & Clear & \\
\hline HR & 621 & 3.55 & & & & & & & $\mathrm{~b} / 1-2$ & & \\
\hline $\mathrm{KD}$ & 522 & 2.9 & & & & & & & & Cirrhosis & \\
\hline $\mathrm{PF}$ & 655 & 1.5 & & & & & & & & $\mathrm{a} / 1$ & \\
\hline $\mathrm{PB}$ & 320 & 1.2 & & & & & & & & Clear & \\
\hline SK & 1729 & 3.2 & & & & & & & $\mathrm{RB} / \mathrm{BE}$ & & \\
\hline WG & 354 & 1.4 & & & & & & & & Cirrhosis & \\
\hline WJ & 84 & 0.7 & & & & & & & & $\mathrm{~b} / 0$ & \\
\hline ZW & 252 & 1.2 & & & & & & & $\mathrm{RB} / \mathrm{BE}$ & & \\
\hline
\end{tabular}

Histological grades a-c and staging from 0 to 4 was based on a proposed classification ${ }^{25}$ as described in Patients and methods. *Alanine aminotransferase (ALT) concentration in U/1 (normal range 0-22).

†Total bilirubin concentration in $\mathrm{mg} / \mathrm{dl}$.

$\mathrm{NA}$, not available; RB/BE, refused biopsy/biochemical evidence of chronic HCV infection; LTX, liver transplant.

egories: minimal chronic hepatitis; mild chronic hepatitis; and moderate chronic hepatitis. Histological staging was based on the extent of fibrosis and development of cirrhosis: fibrosis $0 / 1$, no or mild fibrosis; fibrosis 2, moderate fibrosis; fibrosis 3, severe fibrosis; and fibrosis 4 , fully established cirrhosis.

\section{Results}

CLINICAL FINDINGS

At the time of examination the mean age of the 20 individuals was 42 years (range 37-53); there were two women and 18 men. Of the 20 patients studied 16 were asymptomatic. Four patients complained of fatigue, three of whom also had loss of libido and impotence. All four symptomatic patients were found to have liver cirrhosis. Two patients had a history of heavy alcohol consumption. One patient presented with end stage liver disease following a period of heavy alcohol consumption for the two years prior to review, and the other, who drank more than $80 \mathrm{~g}$ alcohol daily, was found to have moderate chronic hepatitis and moderate fibrosis on liver biopsy. The two patients who refused liver biopsy showed structural changes of the liver parenchyma on ultrasound examination. Two patients have received liver transplants for decompensated cirrhosis: one in 1994, 16 years after infection; and one has recently been transplanted. Hepatocellular carcinoma could not be detected in any of the subjects as judged by $\alpha$ fetoprotein, ultrasound examination, and/or computed tomography.

None of the patients had any comorbidity or received immunosupressive treatment that might be expected to alter disease progression and none of the patients had received antiviral therapy prior to study entry in 1994.

SEROLOGICAL/VIROLOGICAL FINDINGS

At presentation, 18/20 individuals had abnormal aminotransferase activity. All subjects were found to be positive for antibodies to HCV. HCV RNA was detected in 17 patients and $\mathrm{HCV}$ genotyping showed infection with type 1a according to the classification proposed by Simmonds and colleagues ${ }^{26}$ in each case. Three patients tested repeatedly negative for $\mathrm{HCV}$ RNA, one of them with end stage liver disease. None of the patients had evidence of any other cause of liver disease including chronic HBV infection (two subjects had evidence of previous HBV infection with detectable HBV core antibody but were HBsAg negative), haemochromatosis, Wilson's disease, $\alpha$-1-antitrypsin deficiency, and autoimmune chronic hepatitis. All subjects tested negative for HIV infection.

HISTOPATHOLOGICAL FINDINGS

Histological evaluation in patients in whom liver biopsy was performed between 1994 and 1996 revealed minimal changes in two, mild changes in seven, chronic active hepatitis in four, and cirrhosis in one. In two patients showing clinical and biochemical signs of liver cirrhosis, biopsy could not be performed because of abnormal coagulation tests. Serial liver biopsies, performed in 11 patients, showed amelioration of histopathological changes in four patients and deterioration in five. In two patients there were no changes in the grading of inflammatory activity (table 1). In one case there was no histological progression of liver disease over 11 years between 1978 and 1989 but over the next five years the disease progressed to decompensated cirrhosis needing liver transplantation. No other cause of liver disease was found in this case and no cause for the accelerated disease progression was apparent.

\section{CORRELATION BETWEEN ACUTE ILINESS AND}

CLINICAL COURSE

No correlation was found between symptoms at presentation in $1977 / 78$ or laboratory parameters at the time of acute illness (including peak alanine aminotransferase and bilirubin) and subsequent disease progression. Nine patients had liver biopsies performed during the acute illness with considerable variation in disease staging and grading (table 1). 
No correlation was found between either stage or grade and subsequent outcome.

Of the two patients who cleared hepatitis C viraemia with no evidence of liver disease, one was asymptomatic during the acute illness and one had nausea, fatigue, and arthralgia.

\section{Discussion}

Hepatitis C is an infection with a variable course that can lead to chronic hepatitis, end stage liver disease, and hepatocellular carcinoma. ${ }^{5-11}$ Chronic HCV infection is often an insidious illness with a slow rate of progression in the majority of patients during the first two decades after acute onset of the disease. ${ }^{5}$ Several studies ${ }^{5-11}$ have focused on the different course of chronic HCV infection but reasons for different disease profiles are still unclear.

This study found evidence that the outbreak of non-A, non-B hepatitis in a plasmapheresis centre between 1977 and 1978 was due to a single source with all viraemic patients being infected with genotype 1a. Eighteen years later $90 \%$ of this cohort had evidence of chronic $\mathrm{HCV}$ infection. Progressive liver disease was found in $50 \%$ of these individuals and $20 \%$ had liver cirrhosis. This rate of progression is in contrast to some previous reports ${ }^{71}{ }^{11}$ but consistent with data from Tremolada and colleagues $^{8}$ and Tong and colleagues. ${ }^{9}$

In keeping with other reports ${ }^{627}$ female sex was found to be associated with an improved outcome. One of the women involved in this outbreak cleared detectable virus and had no evidence of chronic infection and the second had only very mild changes in liver histology.

As reported previously, chronic alcohol consumption must be considered a strong risk factor for disease progression in patients chronically infected with $\mathrm{HCV}^{562829}$ with both patients who drank over $80 \mathrm{~g}$ alcohol daily having a poor outcome: one developed end stage liver disease requiring transplantation after two years heavy consumption, and the other has an active hepatitis.

Increasing age at time of infection has been identified to be an important risk factor for an increased rate of disease progression. ${ }^{6}$ However, our study subjects were mostly students at the time of donating plasma and were all 35 years of age or less at time of infection; despite this $20 \%$ had developed cirrhosis within 18 years of infection. Symptoms in our cohort were rare with only four patients complaining of fatigue, all of whom had evidence of cirrhosis. This is in keeping with previous findings that symptoms are poor predictors of chronic $\mathrm{HCV}$ infection and frequently only arise with advanced liver disease. ${ }^{30}$

The recent paper by Poynard et al found that progression of fibrosis was almost linear with time in a cohort of patients with either paired liver biopsies or where duration of infection could be estimated. ${ }^{6}$ In our cohort fibrosis scores did not progress linearly with time and actually decreased in two cases. In one case fibrosis remained almost static for 11 years before progressing rapidly to advanced cirrhosis within five years in the absence of any cofactors including alcohol, drugs, or other disease. These findings suggest that rates of progression are not always linear and accelerated progression can occur in some cases without clear triggers, which emphasises the need for continuing follow up of patients even when disease progression appears to be slow.

Unlike HIV infection where an acute seroconversion illness is often associated with rapid disease progression, ${ }^{31} 32$ we found no association between the subsequent clinical course and the severity of initial presenting symptoms, laboratory parameters, or histological features of acute hepatitis.

Our findings show that widely different patterns of disease progression occur in a group of patients, all infected with the same virus strain at the same time even though they all had similar epidemiological backgrounds. This supports the notion that host factors play a critical role in determining the natural history of disease progression for each individual following hepatitis $\mathrm{C}$ virus infection. Disease progression clearly occurs in the absence of accepted cofactors such as alcohol and the precise nature of the host factors involved remains to be elucidated. Possible candidate factors include the genes involved in determining the host's immune response to $\mathrm{HCV}$; in keeping with this there is growing awareness of the importance of host HLA class II type in determining susceptibility to and outcome of HCV infection. ${ }^{33} 34$ The great variability in the prognosis of chronic $\mathrm{HCV}$ infection and the problems in predicting who is likely to develop severe disease makes decisions regarding the need for expensive antiviral treatment difficult. An improved understanding of the factors which determine differences in the natural course of the disease is needed.

1 Van der Poel CL, Cuypers HT, Reesink HW. Hepatitis C virus six years on. Lancet 1994;344:1475-9.

2 Choo Q-L, Kuo G, Weiner AJ, et al. Isolation of a cDNA clone derived from a blood borne non-A, non-B viral hepatitis genome. Science 1989;244:359-62.

3 Alter MJ, Margolis HS, Krawezynski K, et al. The natural history of community-acquired hepatitis $\mathrm{C}$ in the United States. The Sentinel Counties Chronic non-A, non-B Hepatitis Study Team. N Engl f Med 1992;32:1899-905.

4 Cory-Cantilena C, VanRaden M, Gibble J, et al. Routes of infection, viremia, and liver disease in blood donors found to have hepatitis C virus liver infection. N Engl F Med 1996; 344:1691-6.

5 Di Bisceglie AM, Goodman ZD, Ishak KG, et al. Long-term clinical and histopathological follow-up of chronic posttransfusion hepatitis. Hepatology 1991;14:969-74.

6 Poynard T, Bedossa P, Opolon P, for the OBSVIRC, METAVIR, CLINIVIR and DOSVIRC groups. Natural history of liver progression in patients with chronic hepatitis C. Lancet 1997;349:825-32.

7 Seef LB, Buskell-Bales Z, Wright EC, et al, and the National Heart, Lung and Blood Institute study group. Long-term mortality after transfusion associated non-A, non-B hepatitis. N Engl F Med 1992;327:1906-11.

8 Tremolada F, Casarin C, Alberti A, et al. Long-term follow-up of non-A, non-B (type C) post-transfusion hepatitis. F Hepatol 1992;16:273-81

9 Tong MJ, El-Farra NS, Reikes AR, et al. Clinical outcomes after transfusion-associated hepatitis C. $N$ Engl $\mathcal{F}$ Med 1995;332:1463-6.

10 Takahashi M, Yamada G, Miyamoto R, et al. Natural course of chronic hepatitis C. Am f Gastroenterol 1993;88:240-3.

11 Crowe J, Doyle C, Fielding JF, et al. Presentation of hepatitis $\mathrm{C}$ in a unique uniform cohort 17 years from inoculation [abstract]. Gastroenterology 1995;108:A1054.

12 Di Bisceglie AM. Hepatitis C and hepatocellular carcinoma. Semin Liver Dis 1995;15:64-9.

13 Kiyosawa K, Sodeyama T, Tanaka E, et al. Interrelationship of blood transfusion, non-A, non-B hepatitis and hepatocellular carcinoma: analysis by detection of antibody to hepatitis C virus. Hepatology 1990;12:671-5.

14 Tong MJ, el Farra NS. Clinical sequelae of hepatitis C aquired from injection drug use. West f Med 1996;164:399404. 
15 Dusheiko G, Schmilovitz Weiss H, Brown D, et al. Hepatitis $C$ virus genotypes: an investigation of type-specific differences in geographic origin and disease. Hepatology 1994;19:13-18

16 Gretch D, Corey I, Wilson J, et al. Assessment of hepatitis C virus RNA levels by quantitative competitive RNA polymerase chain reaction: high-titer viremia correlates
with advanced stage of disease. F Infect Dis 1994;169:1219with
25 .

17 Kato N, Yokosuka O, Hosoda K, et al. Quantification of hepatitis C virus by competitive reverse transcription polymerase chain reaction: increase of the virus in advanced liver disease. Hepatology 1993;18:16-20.

18 Honda M, Kaneko S, Sakai A, et al. Degree of diversity of hepatitis $\mathrm{C}$ quasispecies and progression of liver disease. Hepatology 1994;20:1148-51.

19 Farci P, Melpolder JC, Shimolda A, et al. Studies of HCV quasispecies in patients with acute resolving hepatitis compared with those who progress to chronic hepatitis. pared with those who
Hepatology 1996;24:350A.

20 Kobayashi M, Tanaka E, Sodeyama $\mathrm{T}$, et al. The natural course of chronic hepatitis C: a comparison between patients with genotypes 1 and 2 hepatitis $\mathrm{C}$ viruses. Hepapatients with genotype

21 Liaw Y-F. Role of hepatitis C virus in dual and triple hepatitis virus infection. Hepatology 1995;22:1101-8.

22 Telfer P, Sabin C, Devereux H, et al. the progression of HCV-associated liver disease in a cohort of haemophilic patients. Br f Haematol 1994;87:555-61.

23 Muss N, Frösner G, Sandhofer F. Epidemic outbreak of a non-a, non-B hepatitis in a plasmapheresis center. Epidemiological observations. Infection 1985;2:57-60.
24 Simmonds P, McOmish F, Yap PL, et al. Sequence variability in the $5^{\prime}$ non-coding region of hepatitis $C$ virus. Identification of a new virus type and restrictions on sequence diversity. 7 Gen Virol 1993;74:661-8.

25 Desmet VJ, Gerber M, Hoofnagle JH, et al. Classification of chronic hepatitis: diagnosis, grading and staging. Hepatology 1994;19:1513-20.

26 Simmonds P, Alberti A, Alter HJ, et al. A proposed system for the nomenclature of hepatitis $\mathrm{C}$ viral genotypes. Hepatology 1994;19:1321-4

27 Dittmann S, Roggendorf M, Dürkop J, et al. Long-term persistence of hepatitis $C$ virus antibodies in a single source outbreak. F Hepatol 1991;13:323-7.

28 Oshita M, Hayashi N, Kasahara A, et al. Increased serum hepatitis C virus levels among alcoholic patients with chronic hepatitis C. Hepatology 1994;20:1015-20.

29 Noda K, Yoshihara H, Suzuki K, et al. Progression of type C chronic hepatitis to liver cirrhosis and hepatocellular carcinoma-its relationship to alcohol drinking and the age of transfusion. Alcohol Exp Res 1996;20(suppl):95-100A

30 Di Bisceglie AM. Hepatitis C. Lancet 1998;351:351-6.

31 Pederson C, Linhardt PO, Jensen BL, et al. Clincal course of primary HIV infection: consequences for subsequent course of infection. BM7 1989;299:154-7

32 Tindall B, Cooper DA. Primary HIV infection: host responses and intervention strategies. AIDS 1991;5:1-14

33 Cramp ME, Carucci P, Donaldson PT, et al. HLA class II alleles and spontaneous clearance of hepatitis $\mathrm{C}$ virus [abstract]. F Hepatol 1997;26:81.

34 Zavaglia C, Martinetti M, Silini E, et al. Association between HLA class II alleles and protection from or susceptibility to chronic hepatitis C. F Hepatol 1998;28:1-7. 